\title{
Gaining a better understanding of the support function of oncology nurse navigators from their own perspective and that of people living with cancer: Part 1
}

by Johanne Hébert, RN, MSc, PhD-in-Nursing Student, and Lise Fillion RN, PhD(Psychology)

\begin{abstract}
Individuals living with cancer have a wide range of needs throughout the disease trajectory. To better meet them, the Quebec Cancer Control Program (PQLC) implemented the oncology nurse navigator role. While this practitioner has already been integrated into the majority of oncology teams, the role still lacks precision when it comes to its functions within care teams. The support function that deals indiscriminately with "the full spectrum of care and services" consolidated under the larger constructs of adaptation and rehabilitation provided to the individual with cancer and their loved ones requires professional skills and organizational resources, which would improve with clarifying.

The goal of this study is to better understand the oncology nurse navigator (ONN) support function, first from the perspective of individuals living with cancer and, second, from the perspective of ONNs themselves. The first objective, detailed in this first part of two, is to explore, from the perspective of people living with cancer, the nature of their needs and support provided by the ONN along the disease trajectory. In all, five individuals living with cancer and provided with an ONN were recruited. The participants expressed support needs at all levels regarding the ONN particularly in the emotional (56\%) and informational areas. Moreover results suggest that symptom management (physical area) and all-around coordination (care interventions, appointments, exams, practitioners) in the practical area are paramount throughout the care trajectory.
\end{abstract}

Following a study on the needs of people living with cancer (Fraser, 1995), the PQLC-French acronym of the Quebec cancer control program-(PQLC, 1998) was instituted to promote the implementation of an integrated network of care and services

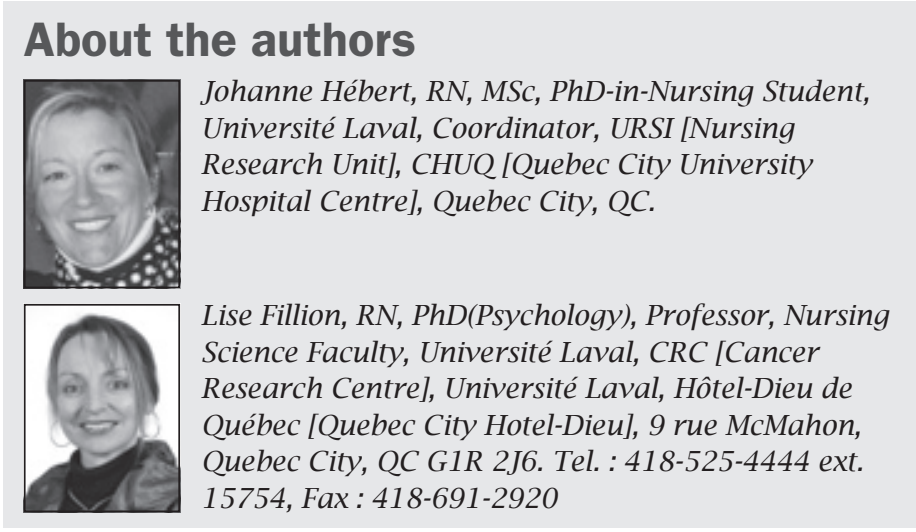

centering on the patients and their loved ones and to better meet the needs in this population. Among the issues raised by people living with cancer were the lack of humanity in communicating diagnosis and the lack of contact throughout the care trajectory, the lack of support in the emotional, psychosocial, existential, material and practical areas, as well as the lack of information on the disease, treatments as well as resources and services provided in the health care network. Furthermore, several gaps were observed in the organization of services: follow-up of patients is insufficient, communication between practitioners is deficient, referral to other professionals is done informally, and service accessibility is not ensured nor is it uniform. The "intervenant pivot en oncologie" (i.e., "oncology patient navigator" in French) is a key element of the priority recommendations for the program. In Quebec, this role has never been carried out by anyone but a nurse. Thus, the role was assigned to specialized oncology nurses and was renamed "infirmière pivot en oncologie" (i.e., "oncology patient-navigator nurse" in English) (Fillion et al., 2006).

\section{The concept of need}

Every day individuals act to meet their needs in the physical, psychological, emotional, social and spiritual areas. They deploy strategies with the aim to satisfy those needs and to adapt to changes in their environment and to the attending demands (Maslow, 1998).

The concept of need was at the root of a nursing focus of attention centring on the human being. Patient-centred care forms the basis for this discipline (Kérouac, Pépin, Ducharme, \& Major, 2003). Care starts with assessing the needs of the individual and the factors that may influence them in a given situation or set of life circumstances (Richardson, Medina, Brown, \& Sitza, 2007a).

According to Adam (1991), the concept of need refers to a necessity rather than a lack. The notion of "necessity" appears to be a useful dimension in defining need, as this conceptualization suggests that the care provider, the ONN in this study, must be able to detect the need and implement effective strategies to meet and satisfy it. Last, the need can be defined as an essential condition for the individual living with cancer, which remains unmet (Hileman, Lackey, \& Hassanein, 1992).

When an extreme life event such as a cancer diagnosis occurs, it is possible that the individual's needs are not met. To satisfy these needs, the individual must access new abilities, mobilize new coping strategies or seek out somebody else's help and support. If the needs remain unmet, the individual may experience emotional distress and present with coping problems; people with cancer often express expectations of support on the part of caregivers (Fitch, Porter, \& Page, 2008).

Although the concept of need is well described in the literature, the concept of support is linked indiscriminately to "the full spectrum of care and services" consolidated under the larger 
constructs of adaptation and rehabilitation provided to individuals with cancer and their loved ones (Direction de la lutte contre le cancer, Comité de soutien, d'adaptation et de réadaptation, 2005a (i.e. the Quebec Cancer Control Branch's Support, Coping and Rehabilitation Committee). It is a global concept that describes all of the assistance provided to meet the needs of people with cancer and their loved ones (Fitch, 2008). By taking this definition as a foundation and by emulating the ONN's job description, as proposed by the CEPIO (Direction de la lutte contre le cancer, 2005) [French acronym of the Committee on the evolution of oncology nursing practice], the ONN's support function could include assessment, screening, intervention and referral tasks.

\section{Conceptual frameworks for the study}

Fitch's Supportive Care Framework (1994) has been chosen to conceptualize the ONN's support function and determine the practical interventions that will help satisfy the needs. This framework advocates a holistic approach where one must pay attention to all of the needs of the individual with cancer and their loved ones along the disease trajectory. The framework also borrows cognitive assessment concepts and coping strategies from Lazarus and Folkman's (1984) intermediate stress theory. According to this framework, the support function corresponds to detecting needs and implementing effective strategies to meet them either through direct interventions or through referrals.

\section{Literature review}

A cancer diagnosis affects many aspects of everyday life for the affected individual and may give rise to many types of needs. Needs vary from one person to the next (Kerr, Harrison, \& Medves, 2004; Liao, Chen, Chen, \& Chen, 2007), are influenced by various psychosocial factors including age, personality, education, social support and coping strategies (Fitch, 2008; Kerr et al., 2004). They also vary based on biological factors such as cancer type and severity, and associated medical treatments (Griffiths, Willard, Burgess, Amir, \& Luker, 2007; Kerr, Harrison, Medves, Tranmer, \& Fitch, 2007; Steele \& Fitch, 2008; Voogt, van Leeuwen, Visser, van der Heide, \& van der Maas, 2005); the needs increase in intensity and importance throughout the disease trajectory (Kerr et al., 2007).

In this study, support needs are presented according to the categories used by Fitch (1994) in her model, i.e., physical, informational, emotional, psychosocial, spiritual and practical areas. In the area of physical needs, the literature highlights the presence of various types of physical symptoms associated with both the illness and the treatments, which the majority of people with cancer face regularly throughout the care continuum. For example, the study by Snyder, Garrett-Mayer, Brahmer, Carducci, Pili, Stearns and collaborators (2008) indicates that the symptoms of fatigue, pain and loss of appetite are negatively associated with the person's global level of functioning (physical, role-related, emotional, social and cognitive); that many unmet physical and everyday needs are associated with poor physical, role and cognitive functioning, and that sleeping problems are closely related to several unmet needs.

Thus, it is not surprising that symptom management is a major component and a daily challenge for oncology nurses in general and for ONNs in particular. They must recognize and assess these signs and symptoms and manage them adequately to allow for a quick and effective intervention strategy.

In addition to physical needs, many studies emphasize the presence of information needs throughout the care trajectory. For example, some studies state that certain individuals want to receive detailed explanations on the physical symptoms, exams, procedures and side effects of the treatments linked to their type of cancer in order to reduce confusion and anxiety and feel a sense of control over their situation (Ahlberg, Ekman, \& GastonJohansson, 2005; Liu, Mok \& Wong, 2005). A quick assessment of information needs is thus recommended in order to adapt the nature of information to the personal needs of the individual with cancer (Nikoletti, Kristjanson, Tataryn, McPhee, \& Burt, 2003).

Several studies draw attention to emotional needs and describe the shock, helplessness and numerous challenges often associated with a cancer diagnosis. As an example, Lauver, Connolly-Nelson and Vang (2007) document the emotional needs as they relate to body changes, confronting death, difficulty concentrating and communication problems with their partners. These authors add that uncertainty regarding treatments, follow-up and the nature of symptoms, physical difficulties (including treatment side effects), a sense of loss and uncertainty, as well as worries about relationships with others are all described as major stressors.

In this regard, the study by Manning-Walsh (2005) reveals that close to $98 \%$ of women experience at least one distress symptom. Tiffen, Sharp and O'Toole (2005) report that people with cancer may not express their distress spontaneously and freely without encouragement or a questionnaire.

In the literature, psychosocial needs are described and associated with changes to social activities and roles brought about by the disease and they sometimes require more specialized support care. According to Steele and Fitch (2008), psychosocial interventions such as participating in a peer support group improve the individual with cancer's well-being and quality of life. More specialized support services such as psychotherapy are often available, but too few patients are being referred.

Further to emotional and psychosocial needs, spiritual needs are more often described in connection with palliative care. In their literature review, Kerr and collaborators (2004) stress that spiritual needs are frequently being reported in less detail than the other needs. Taylor (2003) also mentions that individuals living with cancer first look for spiritual support with family members before they will do it with health care professionals. This is consistent with the statements of women living with cancer who report having received spiritual support from some health care professionals with whom they were able to form a conducive relationship (Gould, Wilson, \& Grassau, 2008).

Lastly, practical needs, which refer to the direct assistance provided to accomplish a task or activity in order to reduce the demands placed on the individual, are rarely described in the literature. Janda, Steginga, Dunn, Langbecker, Walker and Eakin (2008) indicate a high percentage of unmet needs in the practical area regarding among other things the use of community services (34\%), taking care of typical activities at home, at work or for one's studies (71\%) and relearning daily living abilities (21\%). Pigott, Pollard, Thomson and Aranda (2008) add other needs such as reimbursement of transportation costs (24\%), treatment trips (21\%), medical certificates (20\%) and daily accommodations (16\%). In both studies by Kerr and colleagues (2004, 2007), participants stress that coping with financial issues is the most difficult of all, the illness of a child affects all spheres of daily living, which gives rise to extra stress in the work-family-home life balance.

The highlighted studies on needs are useful in identifying the nature and variety of cancer patients' needs. However, they do not help in determining the support expectations this population has for ONNs.

\section{Objectives}

The main objective for Part 1 of this study is to explore, from the perspective of people living with cancer, the nature of their needs and that of the support provided by the ONN during the care trajectory. 


\section{Methodology \\ Design}

This study is part of a wider research program dealing on the one hand with completing a descriptive evaluation of the implementation process for the oncology nurse navigators' role within two local oncology teams in the Quebec City area, and on the other hand with conceptualizing the professional role of navigation by comparing different applications of the ONN role in Quebec (local and supraregional team) to the navigation nursing role existing in NovaScotia (Fillion et al., 2009). To investigate the support function as lived by people with cancer and the ONNs, the qualitative descriptive interpretive approach was selected.

\section{Participants}

For this study, two separate groups were chosen, individuals living with cancer and ONNs. Each of the groups is linked to an objective of the study. The first sample was selected among the 18 people with cancer, both men and women, taking part in a larger study in order to maximize the diversity of their sociodemographic and medical characteristics. The second one was selected so as to diversify experience in oncology and areas of practice: local ONNs, ONNs in joint hospital centre-health and social services centre teams and lastly supraregional ONNs.

Data were obtained with two data collection methods, semi-directed individual interviews and sociodemographic data forms. The interviews were conducted with an interview guide developed from the framework. This guide, which includes open questions such as "According to you, what are the ONN's main functions?", does not demand predetermined answers and promotes the free expression of opinion by the participants. As the second data collection method, a sociodemographic data form was used to paint a profile of the participants' personal characteristics.

\section{Procedure}

Individuals living with cancer were recruited thanks to the collaboration of ONNs belonging to two local oncology teams. At a specific stage of the study, ONNs were asked by the research team and their manager to systematically invite new individuals treated for cancer to be contacted to receive information regarding a study. All ONNs in the participating centres were directly contacted by the research team. People interested in participating met with two research assistants with training in interviewing. The interviews with individuals living with cancer were conducted in their own living environment. The research program of which this study is a part was approved by the research ethics committees of the various institutions where data collection was performed.

\section{Data analysis}

Interviews were recorded onto digital media and fully transcribed by a research professional. All transcriptions (verbatims) were analyzed by the research student. Content analysis was inspired by Glaser and Strauss' (1967) grounded theorizing method. Data analysis was conducted by establishing continuous links with the conceptual framework supporting the study, and specifically using the needs categories from Fitch's framework, which allowed for a first encoding. Each data transcription was captured and processed with the NVivo8 software which helped derive quantitative descriptive indicators.

The credibility of the approach was ensured in three ways: 1) triangulation of the populations being studied (ONNs and individuals living with cancer); 2) individual interviews where open questions were asked so as to obtain complete and indepth perceptions of the phenomenon under study; 3) two peer conferencing sessions in the form of presentations and discussions took place in the presence of oncology experts and research professionals. Dependability was sought by 1) using an interview guide; 2) recording the interviews and transcribing them in full;
3) data coding conducted according to Glaser \& Strauss' (1967) method and using a conceptual framework to guide the coding. The following measures were taken to increase confirmability: 1) interrater agreement was done at the stage of precisely encoding the verbatims; 2) recording notes regarding the individuals with cancer and ONNs met, as well as the student researcher's impressions all along the process. Lastly, the transferability criteria were met by carefully selecting the participants, and the design employed allows for a rich description of the phenomenon and the comparison of results with the literature.

\section{Results}

This section begins with a presentation of the participants. Table 1 describes their sociodemographic characteristics. It illustrates the diversity required in both the sociodemographic and medical areas (type and severity of cancer). After that, support needs of people living with cancer are specified.

\begin{tabular}{|c|c|}
\hline Variables & Individuals $(\mathrm{N}=5)$ \\
\hline Age (median) & 57.8 (50-62 years) \\
\hline \multicolumn{2}{|l|}{ Education } \\
\hline$<$ Quebec CEGEP & 3 \\
\hline$\geq$ Quebec CEGEP & 2 \\
\hline \multicolumn{2}{|l|}{ Type de cancer } \\
\hline Colorectal & 3 \\
\hline Lung & 1 \\
\hline Liver & 1 \\
\hline \multicolumn{2}{|l|}{ Severity } \\
\hline Metastases & 3 \\
\hline No metastasis & 2 \\
\hline \multicolumn{2}{|l|}{ Meeting with the ONN } \\
\hline At diagnosis & 2 \\
\hline At beginning of treatments & 3 \\
\hline
\end{tabular}

\section{Support needs of individuals living with cancer}

The definition of needs classification categories was first clarified. Needs relating to symptom management (information, advice and referrals) are placed in the physical needs area. Needs associated with coordination are presented in the practical needs area.

A quantitative indicator (percentage) for estimating support needs was developed from the qualitative data by associating the comments of individuals living with cancer with the various corresponding categories of needs. Each verbatim was classified and compiled as per a needs category, and the distribution of percentages of expressed support needs is illustrated in Figure 1. It can be observed that emotional needs represent more than half of the support needs expressed by individuals living with cancer. These are followed, in order, by information, practical, physical, psychosocial and spiritual needs. 
For each category of needs, themes were extracted from the data before being illustrated with verbatims and presented in Table 2. For emotional needs, three themes emerged: the importance of being able to speak to somebody at any point along the care trajectory; the need to establish a special relationship with the ONN; to feel listened to and reassured at the most difficult times of the disease. All participants highlighted the ONN's presence and emotional support throughout the care trajectory. Furthermore, they all said they appreciated the ONN's availability in case of need.

Information needs came in second place. All the individuals reported they had had a need for information on various topics particularly disease, treatments, medications, available resources and care trajectory. In addition, they appreciate the fact they can ask questions. They also express the feeling that being informed contributes to lessening their anxiety and helps them to progress emotionally. However, it is hard at times to distinguish between emotional needs and information needs.

Concerning practical needs, the individuals describe how useful the ONN is for coordinating appointments, carrying out various procedures and establishing links with practitioners. Individuals with cancer feel that the ONN can help them find the necessary resources "call me she says then I'll find all the resources for your needs (...) no problem, I'll take care of it... and she does" (7).

In the area of physical needs, the participants expressed the need to have access to the ONN to better manage the symptoms associated with the treatment side effects or the disease. Wanting to receive information and advice that are both appropriate for their physical problems was reported by all individuals involved in the study. They appreciate that the ONN consults with other practitioners to provide them with accurate information. However, one must recognize once again that one category of needs can be very closely related to another, in this case, the physical need being very close to the information need itself often linked to emotional need.

Regarding psychosocial needs, the ONN's support has been described as an essential help to better cope with the disease. Furthermore, the patients report that the ONN contributes to restructuring the perception they have about some situations they have experienced which helps them better manage difficult periods "she has a calming effect (...) she dedramatizes situations a great deal and that helps (...) because sometimes, you are in poor spirits" (6). Once again, the existence of connections between emotional needs and psychosocial needs is observed, with a social need being

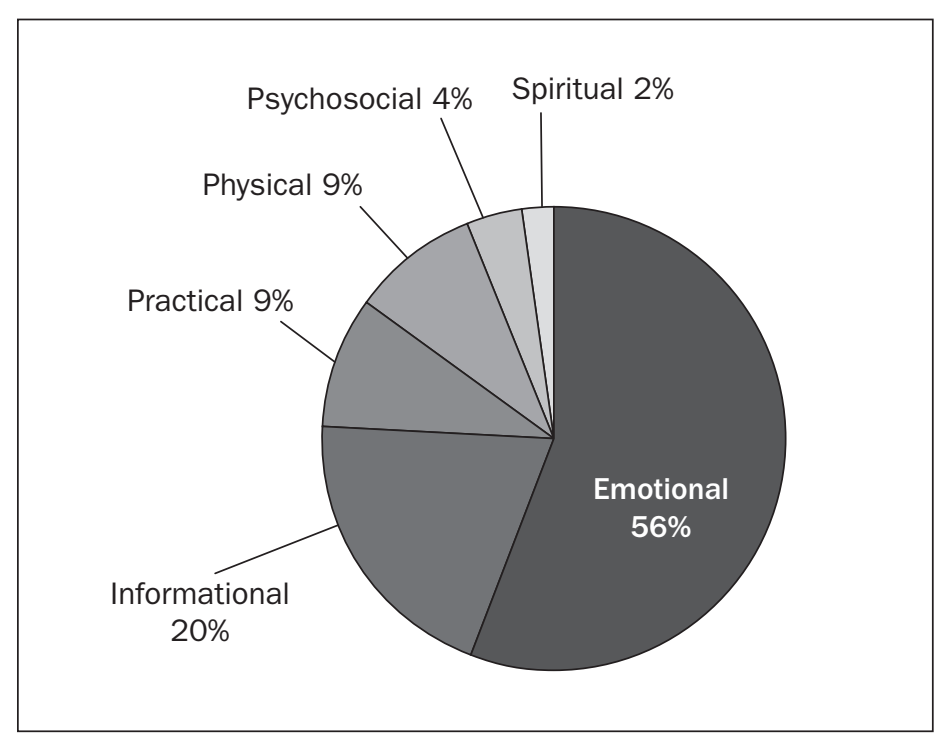

Figure 1. The distribution of support needs as expressed by individuals living with cancer linked to an emotional need in this case. Besides, it is to be noted that spiritual needs are rarely addressed. Some participants clarify the intimate nature of spiritual needs and how deeply personal this process is.

In short, support needs expressed by individuals living with cancer confirm the existence of diverse needs all along the disease continuum. Furthermore, the support the ONN provides to satisfy those needs is described as being useful to actively face the disease and progress through the care trajectory.

\section{Discussion}

The primary objective for this study was to explore the nature of support needs along the disease trajectory from the perspective of individuals living with cancer, and these are discussed in this first article. The results obtained with individuals living with cancer confirm firstly the existence of needs and expectations of support from the ONN throughout the care trajectory in all areas especially emotional and informational needs. In this study, emotional needs top the needs expressed by individuals living with cancer. To meet them, they appreciate the presence of the ONN along the care trajectory, the establishment of a trusting relation and the sense of being listened to, which all promote coping with the disease. The study by Long, Kneafsey, Ryan and Berry (2002), which looked at nursing staff contribution to a rehabilitation team, yielded similar results.

Likewise the need for a vast quantity of information is everpresent and the information provided by the ONN is described as useful for coping with various situations especially symptom management (physical needs). This is hardly surprising, as the literature states that physical changes require mobilizing new behaviours, imply learning and constitute a daily challenge (Ahlberg et al., 2005). Informational support could promote these changes by helping to develop a certain peace of mind, optimism in the face of illness and implementation of active coping strategies (Doll et al., 2007; Kerr et al., 2004).

Moreover, the individuals mention a sense of security and trust in association with the ONN's interventions aimed at meeting their practical needs. In spite of the paucity of studies describing these needs, participants reported numerous interventions in this area. Regarding this matter, Kerr and collaborators (2004) assert that the assessment of needs related to the practical assistance the family requires and to the management of everyday activities must be included in the initial assessment.

When it comes to psychosocial needs, individuals living with cancer appreciate the ONN's encouragement during the most difficult times. She helps them deal with the illness experience by promoting the acceptance of different changes. Some individuals also mentioned the ease of talking to someone from the outside at particularly emotionally charged moments. A recent study (Richardson, Plant, Moore, Medina, Cornwall, \& Recam, 2007b) presents similar results and specifies that this support helps with coping with changes in family roles.

It is worth noting that spiritual needs are described as intimate and personal needs. The participants stress that spirituality is an internal journey and that the ONN does not appear to be the best person to talk about these needs, which is consistent with the findings of some studies (Ahmed, Ahmedzai, Vora, Harrison, \& Paz, 2004; Strang, Strang, \& Ternestedt, 2002).

Individuals living with cancer express many types of needs throughout the disease trajectory. The ONN plays a key role in assessing these needs and in providing support through targeted interventions. Even though the majority of expressed needs are related to the areas of emotional and informational needs, the completion of the study highlights that all needs must be assessed by the ONN in order to enable an intervention strategy that is quick, effective and centred on the needs of the individual living with cancer. 


\begin{tabular}{|c|c|c|}
\hline $\begin{array}{l}\text { Needs } \\
\text { (Fitch, 1994) }\end{array}$ & Emerging themes & Verbatims \\
\hline \multirow{10}{*}{ Emotional } & \multirow{3}{*}{$\begin{array}{l}\text { Need to have somebody } \\
\text { there, to have someone you } \\
\text { can talk to throughout the } \\
\text { care trajectory. }\end{array}$} & "you feel assisted and supported in all that (...) I find her presence important" (5) \\
\hline & & "you don't feel as lonely (...) you feel that she is there for us if we should have a need" (6) \\
\hline & & "I felt the need to hang on, I needed a life buoy and they were the buoy" (9) \\
\hline & \multirow{2}{*}{$\begin{array}{l}\text { Need to take the time to } \\
\text { talk and be listened to }\end{array}$} & $\begin{array}{l}\text { "we need to let our emotions out... I need somebody who is going to listen to me }(\ldots) \text { and I } \\
\text { need to talk too" (7) }\end{array}$ \\
\hline & & "she takes the time it requires (...) she really takes the time" (6) \\
\hline & \multirow{3}{*}{$\begin{array}{l}\text { Need to establish a trusting } \\
\text { relationship, to forge ties }\end{array}$} & "she brings us emotional security... and you know that you can count on her" (6) \\
\hline & & $\begin{array}{l}\text { "I am comfortable asking her certain questions, a bit like I have known her for a very long } \\
\text { time" (5) }\end{array}$ \\
\hline & & $\begin{array}{l}\text { "I feel more nurtured... better understood because she knows everything about my } \\
\text { situation" (6) }\end{array}$ \\
\hline & \multirow{2}{*}{ Need to be reassured } & $\begin{array}{l}\text { "when I was having my chemo treatments, she would come to see me (...) she would } \\
\text { reassure me... it was a lot easier that way" (2) }\end{array}$ \\
\hline & & "if I had a doubt, she would reassure me" (9) \\
\hline \multirow{3}{*}{ Informational } & \multirow{3}{*}{$\begin{array}{l}\text { Need to receive information } \\
\text { and ask questions on } \\
\text { varied topics (disease, } \\
\text { treatments, medication, } \\
\text { diet, available resources, } \\
\text { care trajectory) }\end{array}$} & $\begin{array}{l}\text { "she left me some information (...) regarding the diet, references, reading material (...) } \\
\text { when we got together, we would discuss the disease (...) available services" (5) }\end{array}$ \\
\hline & & $\begin{array}{l}\text { "I was asking myself a lot of questions about all sorts of things (...) I could call her if I had } \\
\text { questions" (6) }\end{array}$ \\
\hline & & $\begin{array}{l}\text { "I know that if there is something I don't understand, (...) if I have any questions, I can call } \\
\text { her" (6) }\end{array}$ \\
\hline \multirow{6}{*}{ Practical } & \multirow{6}{*}{$\begin{array}{l}\text { Need of help to link up with } \\
\text { various practitioners, to } \\
\text { coordinate appointments } \\
\text { and to take steps }\end{array}$} & "she contacted the physiotherapist" (5) \\
\hline & & "she creates the links between myself and the hospital MDs" (9) \\
\hline & & $\begin{array}{l}\text { "she communicated with the oncologist during my chemo (...) she communicated on my } \\
\text { behalf" (5) }\end{array}$ \\
\hline & & $\begin{array}{l}\text { "she would forward information to services and the services would communicate with us" } \\
\text { (5) }\end{array}$ \\
\hline & & "she called my family doctor then I got my appointment at dinner time" (7) \\
\hline & & "on a few occasions, she took steps to clarify some things for me" (2) \\
\hline \multirow{4}{*}{ Physical } & \multirow{4}{*}{$\begin{array}{l}\text { Need of assistance and } \\
\text { advice to reduce the } \\
\text { symptoms associated with } \\
\text { the disease and treatments }\end{array}$} & "she was very useful because I had complications (...) I would call her almost every day" (6) \\
\hline & & $\begin{array}{l}\text { "I called her and I said "I am not doing well at all (...) she replied I'm going to make some } \\
\text { inquiries and call you back (...) she did and told me to go to the hospital" (7) }\end{array}$ \\
\hline & & "she would tell me what to do for all my problems" (6) \\
\hline & & "I would call her to know what to do (...) she was following my case very closely..." (6) \\
\hline \multirow{3}{*}{ Psychosocial } & \multirow{3}{*}{$\begin{array}{l}\text { Need to be encouraged to } \\
\text { deal with the aftermath of } \\
\text { the disease }\end{array}$} & "she helped me carry on... to take it one day at a time" (7) \\
\hline & & "she prevents us from going off course... she keeps a stability of sorts in our journey" (6) \\
\hline & & $\begin{array}{l}\text { "she helped me deal with the disease (...) I did not want to open up to anybody (...) the } \\
\text { shape I am in today and the shape I was in at the beginning, there is a huge difference" (9) }\end{array}$ \\
\hline \multirow{2}{*}{ Spiritual } & \multirow{2}{*}{ Respect for personal choice } & $\begin{array}{l}\text { "I believe in God (...) but that is really an internal journey (...) it's not with an ONN that I } \\
\text { worked on that" (2) }\end{array}$ \\
\hline & & $\begin{array}{l}\text { "for this aspect of life, I am more reserved (...) I live my spirituality the way I want to live it } \\
\text { (...) I am very reserved when it comes to this" (7) }\end{array}$ \\
\hline
\end{tabular}




\section{References}

Ahlberg, K., Ekman, T., \& Gaston-Johansson, F. (2005). Fatigue, psychological distress, coping resources, and functional status during radiotherapy for uterine cancer. Oncology Nursing Forum, 32(3), 633-640.

Ahmed, N., Ahmedzai, S.H., Vora, V., Harrison, V., \& Paz, S. (2004). Supportive care for patients with gastrointestinal cancer (Review). Cochrane Database of Systematic Reviews, 3, art. No.: CD003445. doi:10.1002/14651858.CD003445.pub2

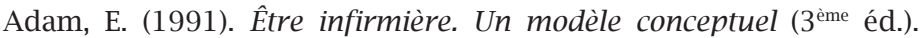
Montréal : Études Vivantes.

Direction de la lutte contre le cancer (2005a). Le soutien, l'adaptation et la réadaptation en oncologie au Québec. Recommandations. Comité de soutien, d'adaptation et de réadaptation (SAR). Québec. Ministère de la Santé et des Services sociaux.

Direction de la lutte contre le cancer (2005b). Pour optimiser la contribution de l'infirmière à la lutte contre le cancer. Comité de l'évolution de la pratique infirmière en oncologie (CEPIO). Québec. Ministère de la Santé et des Services sociaux.

Doll, R., Barroetavena, M.C., Ellwood, A.L., Fillion, L., Habra, M.E., Linden, W., \& Stephen, J. (2007). The Cancer Care Navigator: Toward a conceptual framework for a new role in oncology. Oncology Exchange, 6(4), 28-35.

Fillion, L., Cook, S., Veillette, A.M., Aubin, M., Rainville, F., Doll, R., \& Fitch, M. (2009). Professional navigation framework: Empirical validation with Canadian applications. Manuscrit en préparation.

Fillion, L., de Serres, M., Lapointe-Goupil, R., Bairati, I., Gagnon, P., Deschamps, M. et al. (2006). Implementing the role of patientnavigator nurse at a university hospital centre. Canadian Oncology Nursing Journal, 16(1), 11-17.

Fitch, M.I. (1994). Providing supportive care for individuals living with cancer. Toronto. Cancer Treatment and Research Foundation.

Fitch, M.I. (2008). Supportive care framework. Canadian Oncology Nursing Journal, 18(1), 6-14.

Fitch, M.I., Porter, H.B., \& Page, B.D. (2008). Supportive Care Framework: A foundation for person-centred care. Pembroke, ON: Pappin Communications.

Fraser, A. (1995). Pour une meilleure compréhension des besoins des personnes atteintes de cancer. Québec. Comité consultatif sur le cancer. Ministère de la Santé et des Services sociaux.

Glaser, B.G., \& Strauss, A.L. (1967). The discovery of grounded theory: strategies for qualitative research. Chicago: Aldine.

Gould, J., Wilson, S., \& Grassau, P. (2008). Reflecting on spirituality in the context of breast cancer diagnosis and treatment. Canadian Oncology Nursing Journal, 18(1), 34-39.

Griffiths, J., Willard, C., Burgess, A., Amir, Z., \& Luker, K. (2007). Meeting the ongoing needs of survivors of rarer cancer. European Journal of Oncology Nursing, 11, 434-441.

Hileman, J.W., Lackey, N.R., \& Hassanein, R.S. (1992). Identifying the needs of home caregivers of patients with cancer. Oncology Nursing Forum, 19(5), 771-777.

Janda, M., Steginga, S., Dunn, J., Langbecker, D., Walker, D., \& Eakin, E. (2008). Unmet supportive care needs and interest in services among patients with a brain tumour and their careers. Patient Education and Counseling, 71, 251-258.

Kérouac, S., Pépin, J., Ducharme, F., \& Major, F. (2003). La pensée infirmière ( $2^{\mathrm{e}}$ ed.). Laval : Groupe Beauchemin.

Kerr, L.-M.J., Harrison, M.B., \& Medves, J. (2004). Supportive care needs of parents of children with cancer: transition from diagnosis to treatment. Oncology Nursing Forum, 31(6), 116126.
Kerr, L.-M.J., Harrison, M.B., Medves, J., Tranmer, J.E. \& Fitch, M.I. (2007). Understanding the supportive care needs of parents of children with cancer: an approach to local needs assessment. Journal of Pediatric Oncology Nursing, 24(5), 279-293.

Lauver, D.R., Connolly-Nelson, K., \& Vang, P. (2007). Stressors and coping strategies among female cancer survivors after treatments. Cancer Nursing, 30(2), 101-111.

Lazarus, R., \& Folkman, S. (1984). Stress, appraisal and coping. New York: Springer.

Liao, M.-N., Chen, M.-F., Chen, S.-C., \& Chen, P.-L. (2007). Healthcare and support needs of women with suspected breast cancer. Journal of Advanced Nursing, 60(3), 289-298.

Liu, J.-E., Mok, E., \& Wong, T. (2005). Perceptions of supportive communication in Chinese patients with cancer: Experiences and expectations. Journal of Advanced Nursing, 52(3), 262270.

Long, A.F., Kneafsey, R., Ryan, J., \& Berry, J. (2002). The role of the nurse within the multi-professional rehabilitation team. Journal of Advanced Nursing, 37(1), 70-78.

Manning-Walsh, J. (2005). Social Support as a mediator between symptom distress and quality of life in women with breast cancer. Journal of Obstetric, gynecologic, \& Neonatal Nursing, 34(4), 482-493.

Maslow, A.H. (1998). Toward a psychology of being (3rd ed.). Ontario: John Wiley \& Sons Canada Ltd.

Ministère de la Santé et des Services sociaux. (1998). Programme québécois de lutte contre le cancer. Pour lutter efficacement contre le cancer, formons équipe. Comité consultatif. Bibliothèque Nationale du Québec.

Nikoletti, S., Kristjanson, L.J., Tataryn, D., McPhee, I., \& Burt, L. (2003). Information needs and coping styles of primary family caregivers of women following breast cancer surgery. Oncology Nursing Forum, 30(6), 987-996.

Pigott, C., Pollard, A., Thomson, K., \& Aranda, S. (2008). Unmet needs in cancer patients: Development of a supportive needs screening tool (SNST). Support Care Cancer, 17(1), 33-45.

Richardson, A., Medina, J., Brown, V., \& Sitzia, J. (2007a). Patients' needs assessment in cancer care: A review of assessment tools. Support Cancer Care, 15, 1125-1144.

Richardson, A., Plant, H., Moore, S., Medina, J., Cornwall, A., \& Recam, E. (2007b). Developing supportive care for family members of people with lung cancer: A feasibility study. Support Care Cancer, $15,1259-1269$.

Snyder, C.F., Garrett-Mayer, E., Brahmer, J.R., Carducci, M.A., Pili, R., Stearns, V., et al. (2008). Symptoms, supportive care needs, and function in cancer patients: How are they related? Quality of Life Research, 17, 665-677.

Steele, R., \& Fitch, M.I. (2008). Supportive care needs of women with gynecologic cancer. Cancer Nursing, 31(4), 284-291.

Strang, S., Strang, P., \& Ternestedt, B.M. (2002). Spiritual needs as defined by Swedish nursing staff. Journal of Clinical Nursing, 11 48-57.

Taylor, E.J. (2003). Spiritual needs of patients with cancer and family caregivers. Cancer Nursing, 26(4), 260-266.

Tiffen, J., Sharp, L., \& O’Toole, C. (2005). Depressive symptoms prescreening and postscreening among returning participants in an ovarian cancer early detection program. Cancer Nursing, $28(4), 325-330$

Voogt, E., van Leeuwen, A.F., Visser, A.P., van der Heide, A., \& van der Maas, P.J. (2005). Information needs of patients with incurable cancer. Support Cancer Care, 13, 943-948. 